\title{
PNEUMOMEDIASTINUM AND PNEUMORETROPERITONEUM AS A RESULT OF MEPHEDRONE INTOXICATION — A CASE REPORT.
}

\author{
Perdyan Adrian ${ }^{1}$ / Piątkowska Anna1, Spychalski Piotr², \\ Łaski Dariusz², Łachiński Andrzej J², Kobiela Jarek² \\ ${ }^{1}$ Surgical Scientific Circle, Department of General, Endocrine and Transplant Surgery, Medical University of Gdansk, Poland \\ ${ }^{2}$ Department of General, Endocrine and Transplant Surgery, Medical University of Gdansk, Poland
}

\begin{abstract}
INTRODUCTION: Presence of air in mediastinal space, retroperitoneal space or subcutaneously is a rare condition in majority caused by trauma of airway or gastrointestinal (Gl) tract. Rarely can it occur as a consequence after drug usage.
\end{abstract}

CASE PRESENTATION: We report a non-traumatic occurrence of pneumomediastinum, pneumoretroperitoneum and subcutaneous emphysema in a 27 year-old male patient who had been inhaling mephedrone for 4 days. Patient was admitted to Department of General, Endocrine and Transplant Surgery, Medical University of Gdansk. CT scans of neck, chest and abdomen were performed with suspicion of perforation of GI tract or airways. Perforation was excluded by gastroscopic and bronchoscopic examinations. Patient was treated conservatively with fluids and antibiotic therapy because of no abnormalities besides free air in mentioned cavities. During 6 days of hospitalization patient made a steady recovery and was discharged in good condition.

CONCLUSIONS: The presence of pneumomediastinum, pneumoretroperitoneum and subcutaneous emphysema associated with mephedrone inhalation has been rarely reported in the literature in the past. There are only a few cases describing such complications and medical management required. By reporting this case we would like to emphasize that mentioned symptoms and history of drug use might seem life-threatening, however, this condition may be self-limiting as well. Therefore, good general state can potentially be indication for a watch-and-wait approach with no surgical intervention necessary.

KEY WORDS: spontaneous pneumomediastinum, pneumoretroperitoneum, subcutaneous emphysema, drug abuse, mephedrone

Disaster Emerg Med J 2018; 3(3): 101-105

\section{INTRODUCTION}

A presence of free air in mediastinal space (pneumomediastinum) and in retroperitoneal space (pneumoretroperitoneum) can manifest as tachycardia and chest pain and may need prompt diagnostics and treatment. Trauma, foreign bodies and drug in- toxication are some of the potential causes of these phenomena (Tab. 1, Tab. 2). The latter one most frequently occur in young individuals, especially males [1]. Among vast variety of drugs that can lead to SPM (spontaneous pneumomediastinum) stimulants, drugs such as cocaine are usually responsible 


\begin{tabular}{|c|c|}
\hline CAUSES OF PNEUMORETROPERITONEUM & MECHANISM \\
\hline Disrupted alveoli & $\begin{array}{l}\text { Air migrates via the loosely packed paraesophageal } \\
\text { connective tissue across the diaphragm }\end{array}$ \\
\hline Inflammatory Bowel Disease & \multirow{6}{*}{ Inflammation $\rightarrow$ perforation } \\
\hline Perforation of a duodenal ulcer & \\
\hline Pneumatosis cystoids intestinalis & \\
\hline Necrotizing fasciitis & \\
\hline Abscess formation & \\
\hline Ruptured appendix & \\
\hline Foreign body & \multirow[b]{2}{*}{ Rupture of bowel wall } \\
\hline $\begin{array}{l}\text { latrogenic (PEG placement, ERCP, laparoscopic operations, } \\
\text { sigmoidoscopy, colonoscopy, epidural anesthesia, barium enema) }\end{array}$ & \\
\hline
\end{tabular}

\begin{tabular}{|c|c|}
\hline CAUSES OF PNEUMOMEDIASTINUM & MECHANISM \\
\hline Chest trauma & $\begin{array}{l}\text { Increase of alveolar pressure } \rightarrow \text { rupture of alveoli } \rightarrow \\
\text { releasing air } \rightarrow \text { migration to the mediastinum through } \\
\text { the peribronchial and perivascular sheaths }\end{array}$ \\
\hline Pulmonary disease (asthma, COPD, respiratory infections) & Excessive coughing $\rightarrow$ rupture \\
\hline $\begin{array}{l}\text { Presence of foreign bodies in the airway, iatrogenic (artificial } \\
\text { ventilation, bronchoscopy) }\end{array}$ & Rupture of airways wall \\
\hline Use of recreational drugs & Inhalation $\rightarrow$ alveoli rupture \\
\hline Childbirth, physical effort, excessive vomiting & Valsalva's maneuver \\
\hline
\end{tabular}

[2-3]. Mephedrone (4-methylmethcathinone) is relatively new synthetic cathinone common in recreational use [4]. It has stimulating effect similar to amphetamine (and derivatives) and cocaine. In this report we present a case of pneumomediastinum and pneumoretroperitoneum caused by mephedrone inhalation.

\section{CASE PRESENTATION}

27-years old male was admitted to emergency department with agitation and impaired verbal and logical contact, tachycardia and tachypnoea, throat ache and high body temperature $\left(39.5^{\circ} \mathrm{C}\right)$. Subcutaneous emphysema of neck and chest was noted upon physical examination (Fig. 1A). The following vital signs and laboratory results were recorded: heart rate 78 bpm, blood pressure 140/60, CRP 186, elevated PCT and glucose level. Empirical antibiotic therapy (ceftriaxone + clarithromycin, fluconazole) was administered and later changed to piperacillin/tazobactam + metronidazole due to suspicion of $\mathrm{Gl}$ perforation. Diagnostics were extended by neck, chest and abdomen contrast enhanced $\mathrm{CT}$. Pneumomediastinum (Fig. 2A) and free air in both peritoneum and retroperitoneum were revealed (Fig. 3A). Police report stated that patient was using unknown drugs for past 4 days.

\section{INVESTIGATION}

Gastroscopy and bronchoscopy were performed to exclude the possible GI and airway perforation, however, no abnormalities were found. Initially, at admission, patient experienced delusions (i.e. delusions of reference, he believed that medical staff is working for the police). Normal verbal and logical contact was regained after 24 hours. After the patient regained full consciousness detailed interview was possible — patient admitted to inhaling mephedrone.

\section{TREATMENT}

The patient was treated medically. Antibiotic therapy and fluids were maintained during following 5 days of hospital stay. On the last day of hospitalization, 

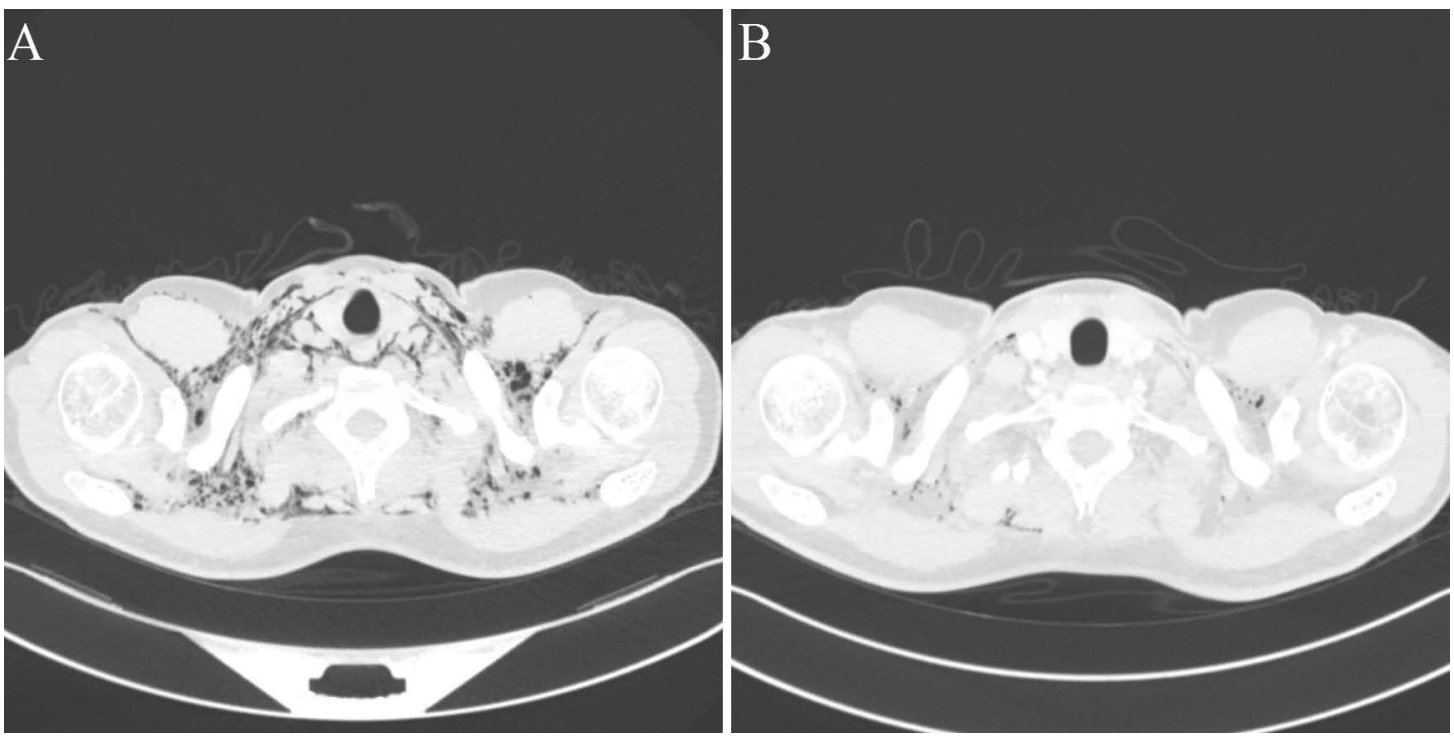

FIGURE 1. CT scan showing subcutaneous emphysema of neck — at diagnosis (A) and (B) before discharge
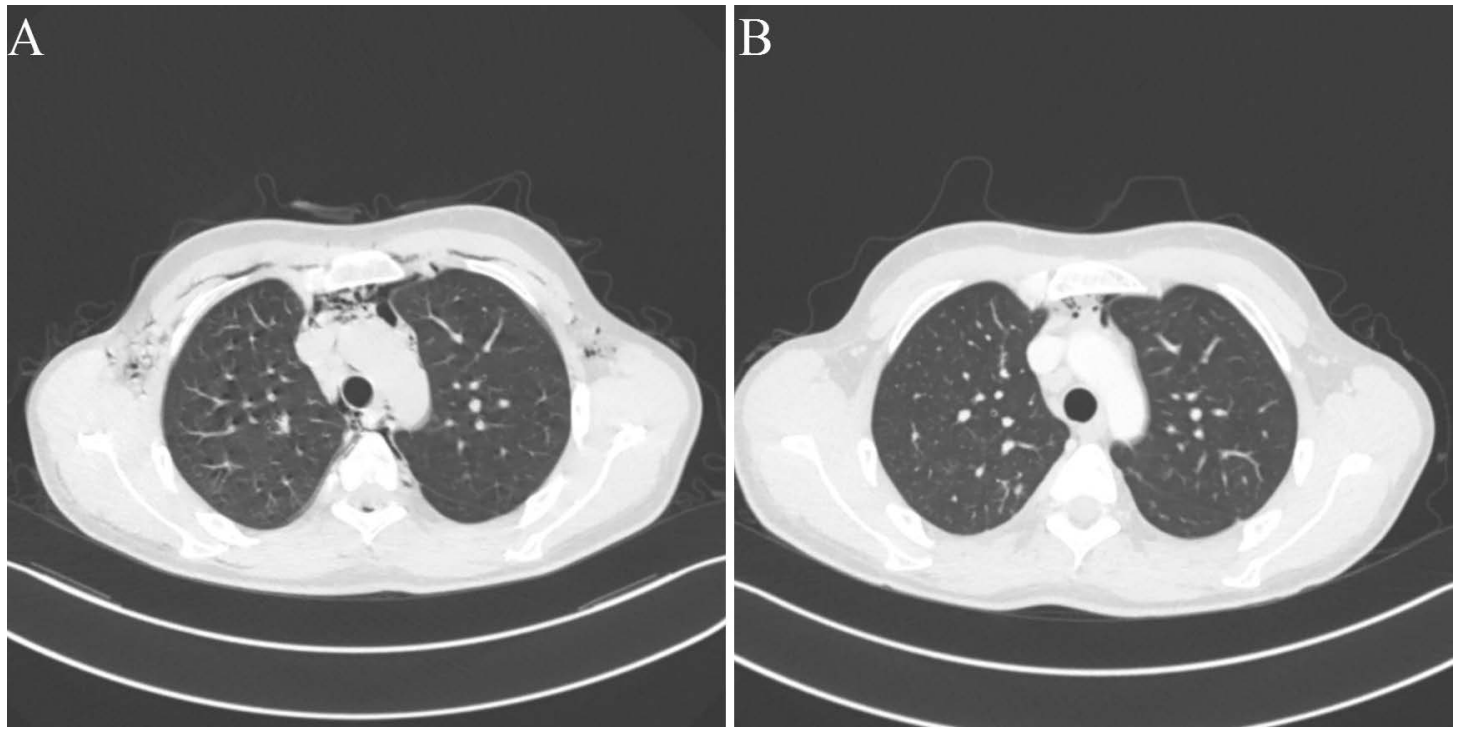

FIGURE 2. CT scan showing pneumomediastinum — at diagnosis (A) and (B) before discharge

a control CT of neck, chest, abdomen and pelvis was performed. The amount of free gas decreased in all locations (Fig.1-3B).

\section{FOLLOW-UP AND OUTCOMES}

Patient was discharged in good condition after 6 days. No adverse and unanticipated events were observed. Patient was not present on follow-up visits.

\section{DISCUSSION}

Pneumomediastinum, pneumoretroperitoneum and subcutaneous emphysema may be symptoms of ei- ther Gl tract or airway perforation. These conditions are potentially life threatening and may need surgical intervention. However, as presented in this case they also may be rare and self-limiting complications of drugs inhalation, which can be treated medically under precise surveillance. Patients seeking aid in emergency department because of SPM were usually admitted with sudden chest pain and dyspnea. Upon exclusion of tension pneumothorax, these symptoms require performing diagnostics to elucidate the reason for presence of free air in and outside of body cavities. As mentioned before Gl tract and airway perforation are some of differential diagnoses and may need surgical intervention or 

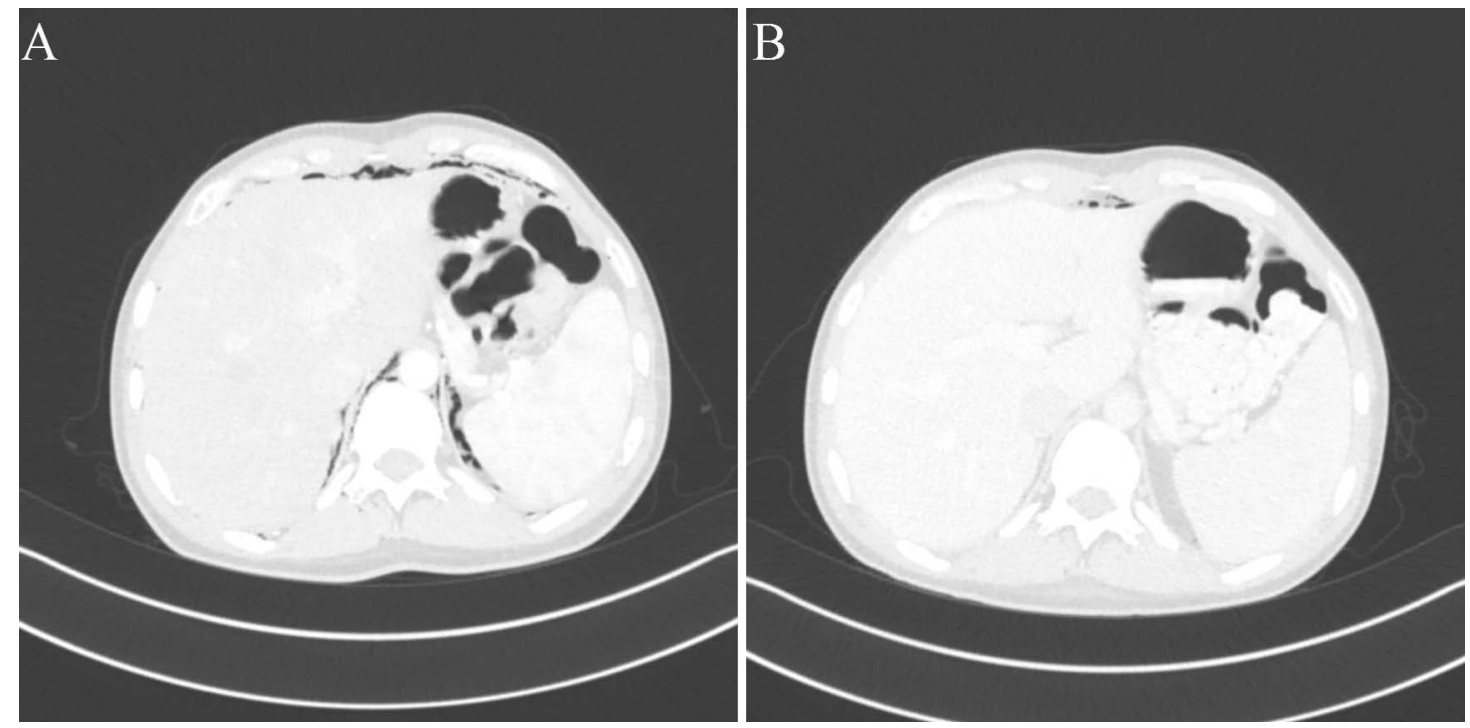

FIGURE 3. CT scan showing pneumoretroperitoneum - at diagnosis (A) and (B) before discharge

chest drainage. Bronchoscopy, gastroscopy, colonoscopy and computed tomography can potentially exclude these pathologies. Once these diagnoses are excluded SPM may be diagnosed.

Drugs, including cocaine, met(amphetamine), MDMA, marihuana and, as presented, mephedrone may cause SPM and consequently pneumomediastinum and subcutaneous emphysema $[5,6,7,8]$. Probable explanation of development SPM as a result of inhalable drug use is that overly distended alveoli rupture under high pressure. Whenever the pressure gradient between the alveoli and the surrounding interstitial space is sufficient the free air then dissects from the ruptured alveoli along the bronchovascular sheaths toward the mediastinum, to produce SPM. This sequence of events is known as the "Macklin effect" which is a result of Valsava's maneuver [9]. Similar effect to Valsalva's maneuver occurs in Muller's maneuver in which chest pressure decreases in perialveolar spaces, and as a consequence, air moves to hypothetic perialveolar space, without penetration of pleura [10]. Furthermore, most probable mechanism of pneumoretroperitoneum occurrence is a translocation of free air form the chest to abdomen by aortic hiatus of the diaphragm. Subcutaneous emphysema is a rare condition that presents as a smooth bulging of the skin with a characteristic palpable crepitation. This can be traumatic, iatrogenic (puncture of the respiratory or Gl tract) or spontaneous [11]. It can occur anywhere in the body but it is the most common in the head and neck region due to the proximity of the airways. Subcutaneous emphysema is not inherently life threatening and the air will be resorbed over time, but it can be uncomfortable for the patient.

Mephedrone (4-methylmethcathinone) is a relatively novel drug, with first reports of use from 2007. Since then, its use is increasing, especially in Europe [12]. It is a synthetic cathinone that has never been licensed as a medicine and no other legitimate uses are known. The effects and the mode of use have similarities with (meth)amphetamine, cocaine and 3,4-methylenedioxymethylamphetamine (MDMA), but its potency is lesser than (meth) amphetamine [4]. Mephedrone can be administered via oral route, nasal insufflation, intramuscular injection, intravenous injection and rectal insertion. The predominant routes are oral ingestion and nasal insufflation [12]. The most common clinical features concerning mephedrone use are agitation, aggression, tachycardia, anxiety, confusion, psychosis and chest pain, however, it may also have no symptoms $[2,3]$. Our patient presented majority of mentioned symptoms including rare ones such as SPM and retroperitoneum.

Most challenging obstacle in this case was the lack of knowledge on the type of substance that the patient was using. Impaired logical contact along with the fact that mephedrone does not come positive on the standard tox-screen delayed precise diagnosis. However, this was not crucial for the treatment, as endoscopic and radiologic examinations confirmed SPM and along with good general condition enabled medical treatment. 
In conclusion, SPM caused by drug abuse usually is a benign condition which does not require surgical intervention nor chest drainage. Patient diagnosed with SPM that is in good general condition, with positive drug abuse history and no apparent perforation of airways or Gl, should be treated conservatively.

\section{LEARNING POINTS}

1. Pneumoretroperitoneum is rare and usually benign complication of drugs inhalation

2. SPM and pneumoretroperitoneum can be treated medically under precise surveillance

3. Self-resolution of these pathologies should be expected

Source of funding — department funding.

Conflict of interest statement: Med. Stud. Perdyan has nothing to disclose. Med. Stud. Piątkowska has nothing to disclose. Dr. Łaski has nothing to disclose. Dr. Spychalski has nothing to disclose. Prof. Łachiński has nothing to disclose. Dr. Kobiela has nothing to disclose.

\section{REFERENCES}

1. Graham R, Bowen N, Singh J. Mephedrone inhalation causes pneumomediastinum. BMJ Case Rep. 2014; 2014, doi: 10.1136/bcr-2014203704, indexed in Pubmed: 24614784.

2. Kouritas VK, Papagiannopoulos K, Lazaridis G, et al. Pneumomediastinum. J Thorac Dis. 2015; 7(Suppl 1): S44-S49, doi: 10.3978/j. issn.2072-1439.2015.01.11, indexed in Pubmed: 25774307.

3. James $D$, Adams RD, Spears $R$, et al. Clinical characteristics of mephedrone toxicity reported to the U.K. National Poisons Information Service. Emerg Med J. 2011; 28(8): 686-689, doi: 10.1136/ emj.2010.096636, indexed in Pubmed: 20798084.
4. Best W, Bodenschatz C, Beran D. Mephedrone: Critical Review Report from the Expert Committee on Drug Dependence Thirty-sixth Meeting (Agenda item 4.12). World Health Organization. 2014: 1-34.

5. Rejali $D$, Glen $P$, Odom N. Pneumomediastinum following ecstasy (methylenedioxymetamphetamine, MDMA) ingestion in two people at the same ,rave'. J Laryngol Otol. 2002; 116(1): 75-76, indexed in Pubmed: 11860664.

6. Kloss $B T$, Broton $C E$, Rodriguez E. Pneumomediastinum from nasal insufflation of cocaine. Int J Emerg Med. 2010; 3(4): 435-437, doi: 10.1007/s12245-010-0205-9, indexed in Pubmed: 21373317.

7. Hazouard E, Koninck JC, Attucci S, et al. Pneumorachis and pneumomediastinum caused by repeated Müller's maneuvers: complications of marijuana smoking. Ann Emerg Med. 2001; 38(6): 694-697, doi: 10.1067/mem.2001.118016, indexed in Pubmed: 11719752.

8. Albanese J, Gross C, Azab M, et al. Spontaneous pneumomediastinum: A rare complication of methamphetamine use. Respir Med Case Rep. 2017; 21: 25-26, doi: 10.1016/j.rmcr.2017.03.007, indexed in Pubmed: 28348951.

9. Romero KJ, Trujillo MH. Spontaneous pneumomediastinum and subcutaneous emphysema in asthma exacerbation: The Macklin effect. Heart Lung. 2010; 39(5): 444-447, doi: 10.1016/j.hrtlng.2009.10.001, indexed in Pubmed: 20561891.

10. Maunder RJ, Pierson DJ, Hudson LD. Subcutaneous and mediastinal emphysema. Pathophysiology, diagnosis, and management. Arch Intern Med. 1984; 144(7): 1447-1453, indexed in Pubmed: 6375617.

11. Maan ZN, D'Souza AR. Spontaneous subcutaneous emphysema associated with mephedrone usage. Ann R Coll Surg Engl. 2012; 94(1): e38-e40, doi: 10.1308/003588412X13171221499108, indexed in Pubmed: 22524925.

12. EMCDDA. Report on the risk assessment of mephedrone in the framework of the Council Decision on new psychoactive substances. European Monitoring Centre for Drugs and Drug Addiction. Luxembourg, Office for Official Publications of the European Communities. 2011, doi: 10.2810/40800. 